Original Article

\title{
Future zoonis forecasting of Betacoronavirus group using phylogenetics and haplotype network analysis
}

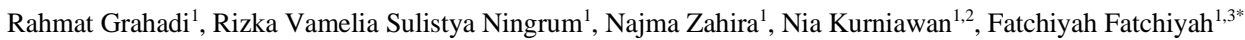 \\ ${ }^{1}$ Department of Biology, Faculty Mathematics and Natural Sciences, Universitas Brawijaya, Malang, Indonesia \\ ${ }^{2}$ NK Research, Faculty Mathematics and Natural Sciences, Universitas Brawijaya, Malang, Indonesia \\ ${ }^{3}$ Research Center of Smart Molecule of Natural Genetics Resources, Universitas Brawijaya, Malang, Indonesia
}

\begin{abstract}
Genetic diversity and species relationship contribute to the inter-species transmission of coronavirus-derived diseases. This research aimed to investigate the probability of newly emergence Betacoronavirus zoonosis according to genetic relationship and haplotype network. A total of 24 Betacoronavirus sequences from different continents were used to construct the phylogenetic tree and the haplotype network. A phylogenetic tree was constructed using the Maximum Likelihood method with RaxML in CIPRES Science Gateway portal and GTRGAMMA+I analysis with 1000 bootstrap. Haplotype Network was done using Network 10.0.0.0 version with median-joining analysis. The result of the phylogenetic and haplotype network formed 4 groups of Betacoronavirus. Group A consisted of Human Coronavirus (HCoV) type OC43 and HKU1, Bovine Coronavirus, and Rodent Coronavirus. Group B consisted of SARS-CoV and SARS-CoV-2. Group C consisted of MERS-CoV (2012 pandemic) and MERS-CoV from camels. Reliable with phylogenetic results, haplotype network also grouped Betacoronaviruses into three groups in accordance with their subgenera. Bovine and Rodent coronavirus are constant to group with previously human coronavirus, i.e. HCoV-OC43 and HCoV-HKU1, respectively. According to the high genetic similarity that the Bovine and Rodent coronavirus may infect to human and provide a new emergence. This study is basic for further research related to inter-species transmission from animal to human.
\end{abstract}

Keywords: Betacoronavirus, haplotype network, phylogenetic, zoonosis

Received: 8 June 2020 Revised: 13 June 2020 Accepted: 15 June 2020

\section{Introduction}

A new Coronavirus ( $\mathrm{CoV})$ became an outbreak since 2019 and infected more than 2 million people in the world. The virus originally came from Wuhan, China then becomes a mass outbreak to other countries. After identified, the virus was named as SARS-CoV-2 with Coronavirus Disease-19 (COVID-19) as it caused illness (Du et al., 2020). Later on, it is known that SARS-CoV-2 belongs to Betacoronavirus, which includes MERS (Middle East Respiratory Syndrome) and SARS (Severe Acute Respiratory Syndrome) (Wassenaar \& Zou, 2020).

Coronavirus is a member of the order Nidovirales, family Coronaviridae, and subfamily Coronavirinae. Coronavirinae then divided into 4 genera: Alphacoronavirus, Betacoronavirus, Gammacoronavirus, and Deltacoronavirus. $\mathrm{CoV}$ has an envelope and also contains a positive sense RNA around $32 \mathrm{~kb}$ length. Structurally, CoV contains envelope protein, membrane protein, nucleocapsid protein, and spike protein (Chen et al., 2020; Cui et al., 2019). The genome of common CoV contains no less than six Open Reading Frames (ORF), with ORF1 encodes non-structural transcriptionreplication complex, while later ORFs encode for viral

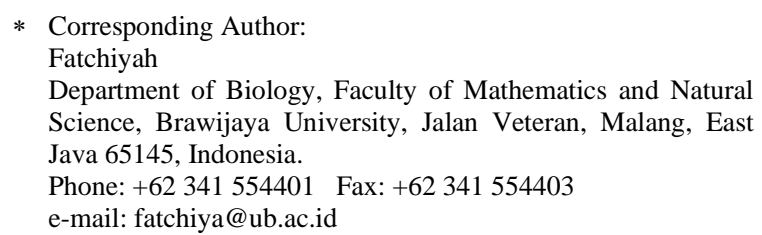

structural protein like Membrane (M), Envelope (E), and Spike (S) proteins (Chen et al., 2020).

Before the COVID-19 outbreak, the emergence of zoonotic diseases transmitted from the animal reservoirs has become a serious threat to public health. For instance, in Betacoronavirus cases only, SARS-CoV and MERS$\mathrm{CoV}$ have been declared as major health problems after infecting many people across the world with high mortality (de Wit et al., 2016). On the other hand, genetic diversity among transmitted viruses from animals was believed to contribute to the zoonosis process ( $\mathrm{Ji}$ et al., 2020; Lu et al., 2018; Woo et al., 2009). Hence, observing previously known animal-derived coronaviruses will provide an insight for predicting future transmission from the original host into human. This study will give some awareness of the possibility of forthcoming coronavirus zoonosis based on genetic similarity and viral species relationship.

\section{Methods}

\section{Data Mining}

Twenty-one whole genomes sequences of Betacoronavirus from several countries in the world were retrieved from GenBank (https://www.ncbi.nlm.nih.gov/genbank/) using a random sampling method to ensure the variability (Yang et al., 2014). Besides, we add all of the SARS-CoV-2 
Indonesian genome (3 genomes, per 6 May 2020) from variances with other countries. This set of data consist of all species of Betacoronavirus and Canine coronavirus from Alphacoronavirus for outgroup (Tab. 1).

\section{Data Analysis}

The sequences were aligned using ClustalW method at CIPRES Science Gateway portal. Polymorphism and gene flow analysis among SARS-CoV-2 sequences was analyzed using DNASP v.6.12.03 (Rozas et al., 2017) to compare its genetic diversity and gene flow between China population and other countries. Gene flow strength $(\mathrm{Nm})$ uses the Nei (1973) criterion formula $(\mathrm{Nm}=[1 / \mathrm{Gst}-1] / 4)$, with $\mathrm{Nm}<1$ considered low gene flow and $\mathrm{Nm}>1$ considered high gene flow (Hwang \& Cho,
GISAID (https://www.gisaid.org/) to compare genome 2018). The phylogenetic tree was constructed using Maximum Likelihood method with RaxML in CIPRES Science Gateway Portal (Stamatakis, 2014). Phylogenetic analysis for Maximum Likelihood uses GTRGAMMA+I algorithms with 1000 bootstrap, the higher bootstrap value more accurate the phylogenetic. The result was visualized using FigTree v1.4.4 and saved in jpg format (Rambaut, 2018). Haplotype Network was conducted using Network 10.0.0.0 version (Fluxus Technology, 2020) with median-joining analysis (Bandelt et al., 1999). NCBI BLAST carried out to analyze potential zoonotic, high genetic similarity more likely transfer to human (NCBI, 2020).

Table 1. The identity of used sequences in this study

\begin{tabular}{|c|c|c|c|c|}
\hline No. & Species & Location & Accession Number & Source \\
\hline 1. & SARS-CoV & China & AY297028.1 & Unpublished \\
\hline 2. & SARS-CoV & Taiwan & AY362699.1 & Unpublished \\
\hline 3. & SARS-CoV & Italy & AY323977.2 & Vicenzi et al., 2004 \\
\hline 4. & SARS-CoV & Canada & NC_004718 & He et al., 2004 \\
\hline 5. & SARS-CoV & Germany & AY291315.1 & Thiel et al., 2003 \\
\hline 6. & SARS-CoV-2 & Japan & LC522975.1 & Unpublished \\
\hline 7. & SARS-CoV-2 & China: Shezhen & MN938384.1 & Chan et al., 2020 \\
\hline 8. & SARS-CoV-2 & Korea & MT039890.1 & Unpublished \\
\hline 9. & SARS-CoV-2 & USA: California & MN994468.1 & Unpublished \\
\hline 10. & SARS-CoV-2 & Sweden & MT093571.1 & Unpublished \\
\hline 11. & SARS-CoV-2 & China: Wuhan & MN908947.3 & Wu et al., 2020 \\
\hline 12. & SARS-CoV-2 & USA: Illinois & MN988713.1 & Unpublished \\
\hline 13. & MERS-CoV & Kenya & MH734115.1 & Ommeh et al, 2018 \\
\hline 14. & MERS-CoV & France & KJ361503.1 & Unplished \\
\hline 15. & MERS-CoV & Thailand & KT225476.2 & Plipat et al, 2017 \\
\hline 16. & MERS-CoV & China & KT006149.2 & Lu et al, 2015 \\
\hline 17. & HCoV-OC43 & USA & KY369905.1 & Unpublished \\
\hline 18. & Bovine Coronavirus & Japan & LC494138.1 & Suzuki et al, 2020 \\
\hline 19. & HCoV-HKU1 & Thailand & MH940245.1 & Unpublished \\
\hline 20. & Rodent Coronavirus & China & KY370043.1 & Wu et al, 2018 \\
\hline 21. & Canine Coronavirus & Italy & KР981644.1 & Decaro et al, 2015 \\
\hline 22. & SARS-CoV-2 & Indonesia: Jakarta 1 & EPI_ISL_435281* & Unpublished \\
\hline 23. & SARS-CoV-2 & Indonesia: Jakarta 2 & EPI_ISL_435282* & Unpublished \\
\hline 24. & SARS-CoV-2 & Indonesia: Jakarta 3 & EPI_ISL_435283* & Unpublished \\
\hline
\end{tabular}

\section{Results}

\section{Alignment and Phylogenetic}

According to alignment result, $\mathrm{HCoV}-\mathrm{OC} 43$, Bovine CoV, HCoV-HKU1, Rodent CoV, SARS-CoV, SARSCoV-2, MERS-CoV, and also Canine CoV showed their distinguishing feature. With a focus on SARS-CoV-2, polymorphic analysis shows there were 29-mutation sites discovered, locating on the ORF1a (Base number 1714, 2767, 2822, 3091, 6381, 6957, 9327, 9828, 11661, 12732, and 13446), ORF1b (13849, 13850, 15275, 16236, 17643, and 18019), S protein $(21705,22692,23277,25255)$ ORF6 (27334), ORF7a (27736), ORF8 (27952), and NC region $(30335,31388,32042,32064$, and 32093).The sample that has the most mutations are SARS-CoV-2 from Korea and Sweden with 8 mutation sites and there is a sample from USA Illinois that doesn't have a mutation. The highest mutation diversity occurred in a sample from Korea that mutates at ORF1a, ORF1b, S Protein, ORF7a, and ORF8. All other samples have at least 2 mutations sites and there is no identical mutation among samples.. (Fig. 1). Further studies that focused on mutation impact is required for revealing the implication of thismutation regarding its contribution to virulence, transmission, or therapy of SARS-CoV-2.

The result from the phylogenetic tree supplemented the alignment result. Generally, all of the analyzed sequences divided into four groups. The first group, which has the largest member consisted of SARS-CoV and SARS-CoV-2. The second group belongs to HcoVOC43, Bovine CoV, HcoV-HKU1, and Rodent CoV. The third group was MERS CoV, while the fourth group was Canine $\mathrm{CoV}$ as out-group. Agreeing with the alignment result, sample number 3 of SARS-CoV-2 Jakarta was disjointed from sample numbers 1 and 2. Besides, SARSCoV-2 from California also separated from Illinois, describing its different features so they were parted. Interestingly, Rodent $\mathrm{CoV}$ was placed in one clade with 
HCoV-HKU1, while Bovine CoV close with HCoV- OC43 in their branch (Fig. 2).

\begin{tabular}{|c|c|c|c|c|c|c|c|c|c|c|c|}
\hline & $\begin{array}{c}1714 \\
\uparrow\end{array}$ & $\begin{array}{c}2767 \\
\uparrow\end{array}$ & 2822 & $\begin{array}{c}3091 \\
\uparrow\end{array}$ & $\begin{array}{c}6381 \\
\uparrow\end{array}$ & $\begin{array}{c}6957 \\
\uparrow\end{array}$ & $\begin{array}{c}9327 \\
\uparrow\end{array}$ & $\begin{array}{c}9828 \\
\uparrow\end{array}$ & $\begin{array}{c}11661 \\
\uparrow\end{array}$ & $\begin{array}{c}12732 \\
\uparrow\end{array}$ & $\begin{array}{c}13446 \\
\uparrow\end{array}$ \\
\hline SAR & $C|A|$ & & & & & & C C A G & & & C|C|C T & \\
\hline SARS-CoV-2 Indonesia: Jakarta 2 & $\begin{array}{lll}A & A & C\end{array}$ & \begin{tabular}{ll|l|l} 
& T
\end{tabular} & G $\mathrm{C} / \mathrm{G} / \mathrm{G}$ & T A T $\mid \mathrm{G}$ & A A $A|C| G$ & \begin{tabular}{|l|l|l}
$T$ & $T$ & $T$ \\
\end{tabular} & c C A G & $\begin{array}{ll}A & A\end{array}$ & $\begin{array}{lll} & T & T\end{array}$ & $\begin{array}{cccc}c & c & c\end{array}$ & \\
\hline SARS-CoV-2 Indonesia: Jakarta 3 & $A$ A A $C$ C $|A|$ & $\mathrm{T}$ A $|\mathrm{C}| \mathrm{T}$ & $\mathrm{G} C \mathrm{G} \mid \mathrm{G}$ & $\mid \mathrm{T}$ A $T$ T $\mathrm{G}$ & A A $|C| G$ & \begin{tabular}{|l|l|l} 
& $T$ & $C$ \\
\end{tabular} & C C A G & $A G|A| T$ & $\mathrm{~T} \mathrm{~T}|\mathrm{~T}|$ & c) c $\mathrm{C} \mathrm{T}$ & \\
\hline SARS-CoV-2 China: Shezhen & A C $|A|$ & $\mathrm{A}|\mathrm{C}| \mathrm{T}$ & (40 & $\mid \mathrm{T} A \mathrm{~A} T \mathrm{G}$ & A A $|C| G$ & \begin{tabular}{|l|l|l} 
& $T$ & $C$ \\
\end{tabular} & TCA G & $A \in|A|$ & 1 & c) c C C T & \\
\hline SARS-Co & A A C $\mid$ A & A $|\mathrm{T}| \mathrm{T}$ & & $\mid \mathrm{T}$ A T $\mathrm{T}$ G & A A $|C| G$ & \begin{tabular}{|l|l|l} 
& $T$ & $T$ \\
\end{tabular} & T C A G & $\mathrm{A} \in \mathrm{A} \mid \mathrm{T}$ & $T T|G| T$ & c $|c| c \mid$ & \\
\hline Wuhan & A A C $|\mathrm{A}|$ & A C $\mathrm{C}$ T & c $G \mid G$ & T A T $T$ G & A A $|\mathrm{C}| \mathrm{G}$ & \begin{tabular}{|l|l|l}
$T$ & $T$ & $C$ \\
\end{tabular} & C C A G & $A G|A| T$ & T T $\mathrm{G}$ T & c) c $\mathrm{c}$ T & \\
\hline SARS-CoV-2 USA: C & $\mathrm{A} C|\mathrm{~A}| \mathrm{H}$ & \begin{tabular}{l|l}
$\mathrm{A}$ & $\mathrm{C}$ \\
$\mathrm{T}$
\end{tabular} & $c|G| G$ & T A T & A A $|C| G$ & \begin{tabular}{|l|l|l} 
& $T$ & $C$ \\
\end{tabular} & c C A G & $A G|A| T$ & T T G TT & c $\mathrm{c}$ C $\mathrm{C} T$ & \\
\hline SARS & $+C|A|$ & $\mathrm{A}|\mathrm{C}| \mathrm{T}$ & & $\mid \mathrm{T}$ A $\mathrm{T} \mid \mathrm{T}$ & $|\mathrm{A} A| \mathrm{T} \mid \mathrm{G}$ & \begin{tabular}{|l|l|l} 
& $T$ & $C$ \\
\end{tabular} & c C A G & \begin{tabular}{ll|l}
$A$ & $A$ & $A$
\end{tabular} & & \begin{tabular}{l|l|l} 
C & T & C T \\
\end{tabular} & \\
\hline SAF & Cla & & $|A| G$ & T A T $\mathrm{G}$ & A C C G & \begin{tabular}{|l|l|l} 
& $T$ & $C$ \\
\end{tabular} & c C A G & $A G|G| T$ & \begin{tabular}{ll|l|l}
$T$ & $T$ & $G$ & $T$
\end{tabular} & c $\mathrm{C}$ C $\mathrm{C}$ T & \\
\hline 0. SA & $\mathrm{c}|\mathrm{A}|$ & (c) $\mathrm{T}$ & G] $G$ & T A T G & $A$ A $A \subset G$ & T T T L LT T & c] C A G & A GLA T T & T T T G T T & c] $\mathrm{C} T$ & C] \\
\hline 1. SARS- & C A & $A C$ & & $T G T A$ & A T G & $\mathrm{CACA}$ & C C A G & $A G A T$ & & C T T T & $C A G$ \\
\hline 2. SAP & C A & & & $T$ G T & & C ACA & C CAG & A G A T & G T T T & C T T T & \\
\hline 3. & & & & & A A T G & $C A C A$ & C C AG & $A G A T$ & G T T T & C T T T & $\mathrm{CAC}$ \\
\hline 4. SARS & C A & $A C$ & G G & $T G T A$ & A A T G & C ACA & $\mathrm{CCAG}$ & $A G A T$ & G T T T & C T T T & CAG \\
\hline 5. SARS- & $\mathrm{ACA}$ & ACT & G G G & T G T A & A A T G & CACA & C C A G & A G A T & G T T T & C T T T & $C A G$ \\
\hline ME & & & & & G G T A & T G T A & $T G A G$ & T C & T T G T & A C T T & C T G \\
\hline $\mathrm{ML}$ & & & TC & T A C T & G G T A & $T \in T A$ & $T$ G A G & $\mathrm{TCC}$ & T T G T & $\mathrm{AC} T \mathrm{~T}$ & C T G \\
\hline 8. $M$ & G T C & 100 & T G & T A C T & G G T A & T G T A & T G A G & T C G T & T T G T & A C T T & C T G \\
\hline MERS & G T C . & & & $T A C T$ & & $T G T A$ & T G A G & & T T G T & A C T T & C T G \\
\hline$R$ & & & & & & G T G C & T A C A & $\mathrm{TC}$ & G T T A & A T A T & G T G \\
\hline & & C T A & C A T G & T G A G & $A A A G$ & T T G T & C ACT & T C C T & A T T A & A T A T & G T G \\
\hline Bovine C & G T T A & & & G G A T & & T T G T & C ACA & & G T A A & TAT & \\
\hline HCoV-OC43 USA & & & & & & & T A C A & & G T A A & A T A T & \\
\hline 4. Canine Coronavirus Italy & A:T T A & TGCT & T C A G & T A A A & C T A G & $A A A C$ & TAAG & $T$ T G T & A TT A & CATT & $\mathrm{C} \mathrm{C} \mathrm{T}$ \\
\hline
\end{tabular}

\section{ORFla}

\begin{tabular}{|c|c|c|c|c|c|}
\hline & 13849,138 & 15275 & 16236 & 17643 & 18019 \\
\hline \\
\hline SARS-LOV-ZInoonessia: Jakara & $2 \mathrm{c} c \mathrm{cT}$ & & & & \\
\hline 3. SARS-CoV-2 Indonesia: Jakarta & $\begin{array}{l}\mathrm{a} \mathbf{c} \\
\mathrm{C}\end{array}$ & $\mathrm{G}|\mathrm{C}| \mathrm{T} \mathrm{G}$ & & A C $A$ A C & CA AA \\
\hline 4. SARS-CoV-2 China: Shezhen & $\mathrm{c} \mid \mathrm{C} \mathrm{T} / \mathrm{T}$ & G $\mathrm{C}$ C T G & $|A| T \mid G T$ & A C C A C & C $|A| A A$ \\
\hline 5. SARS-CoV-2 Japan & $c|c T| T$ & & $|A| T \mid G$ & $\mathrm{~A}|\mathrm{C}| \mathrm{A} \mathrm{C}$ & \\
\hline 6. SARS-CoV-2 China: Wuhan & $c \mid c t / T$ & $\mathrm{G}|\mathrm{C}| \mathrm{T} \mathrm{G}$ & & $A|C| A C$ & c|AAA \\
\hline 7. SARS-CoV-2 USA: California & $c|c t| T$ & & & $A|T| A C$ & \\
\hline 8. SARS-CoV-2 Korea & $c|c T| T$ & & & $A|C| A C$ & A A A \\
\hline SARS-CoV-2 Sweden & & & & & \\
\hline 0. SARS-COV-2 USA: Illinois & clet T & GC T G & Alig & A.ClA C & $A A A$ \\
\hline 11. SARS-CoV Canada & C $\overline{C T} T$ & G C T G & ATGT & $A C A C$ & CTAA \\
\hline 12. SARS-CoV Italy & с ст T & G C T G & A T G T & $\mathrm{ACAC}$ & CTAA \\
\hline 13. SARS-CoV Taiwan & с с T T & & A T G T & $\mathrm{ACAC}$ & CTAA \\
\hline 14. SARS-CoV Germany & с С T T & & & $A C A C$ & \\
\hline 15. SARS-CoV China & & & A T G T & $\mathrm{ACAC}$ & CTAA \\
\hline 16. MERS-CoV China & CTTA & CTG & A A G T & $\mathrm{ACCA}$ & CTAA \\
\hline 17. MERS-CoV Thailand & CTTA & & A A G T & $\mathrm{ACCA}$ & CTAA \\
\hline 18. MERS-CoV France & CTTA & C T T & A A G T & $\mathrm{ACCA}$ & CTAA \\
\hline 19. MERS-CoV Kenya & CTTA & G C T G & A A G T & $A \subset C A$ & CTAA \\
\hline 20. Rodent Coronavirus China & CATA & & & & CTA \\
\hline 21. HCOV-HKU1 Thailand & CTTA & & GTAT & G T T T & CTA \\
\hline 22. Bovine Coronavirus Japan & CATA & $\mathrm{GCGG}$ & & & $\mathrm{CCAA}$ \\
\hline 23. HCoV-OC43 USA & & & & & $\mathrm{CCAA}$ \\
\hline 24. Canine Coronavirus Italy & & $C A G$ & CAGT & G T C T & CTAA \\
\hline
\end{tabular}
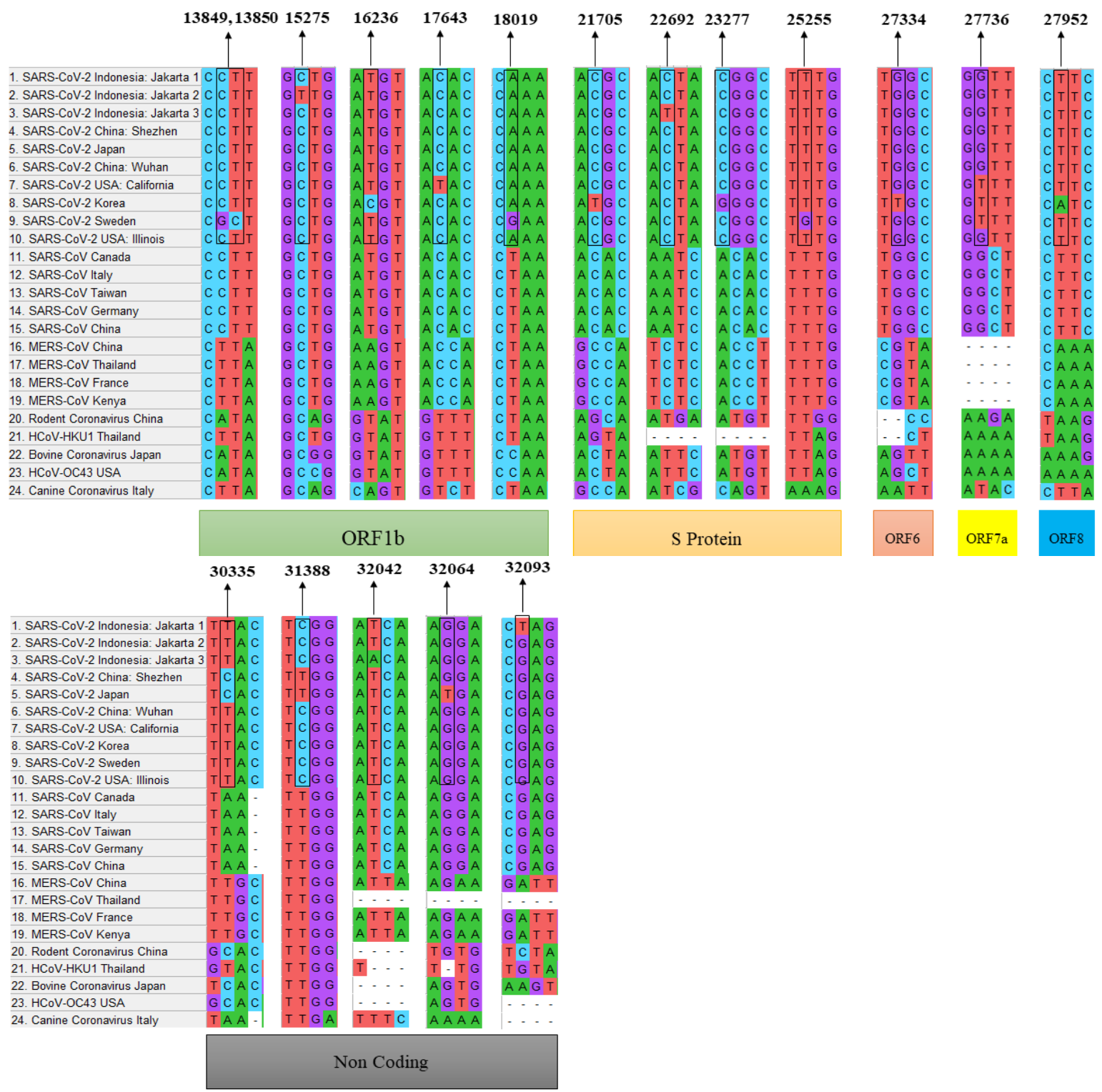

Figure 1. Alignment and mutation sites in SARS-CoV-2 from different countries compared to SARS-CoV, MERS-CoV and other Betacoronaviruses. 


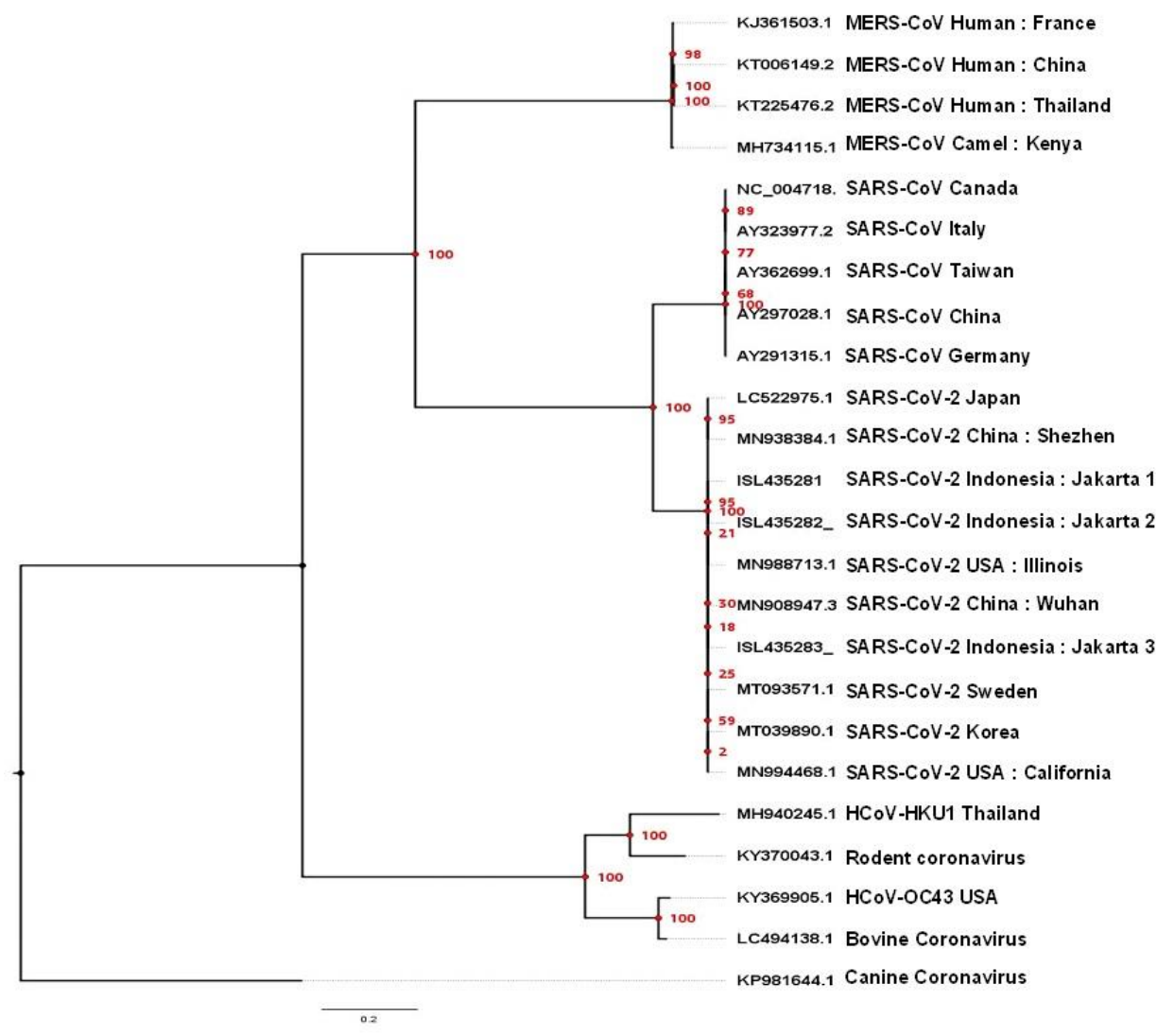

Figure 2. Phylogenetic tree of Betacoronavirus species and Canine Coronavirus as an out-group. Red number shows the bootstrap value that indicates its accuracy.

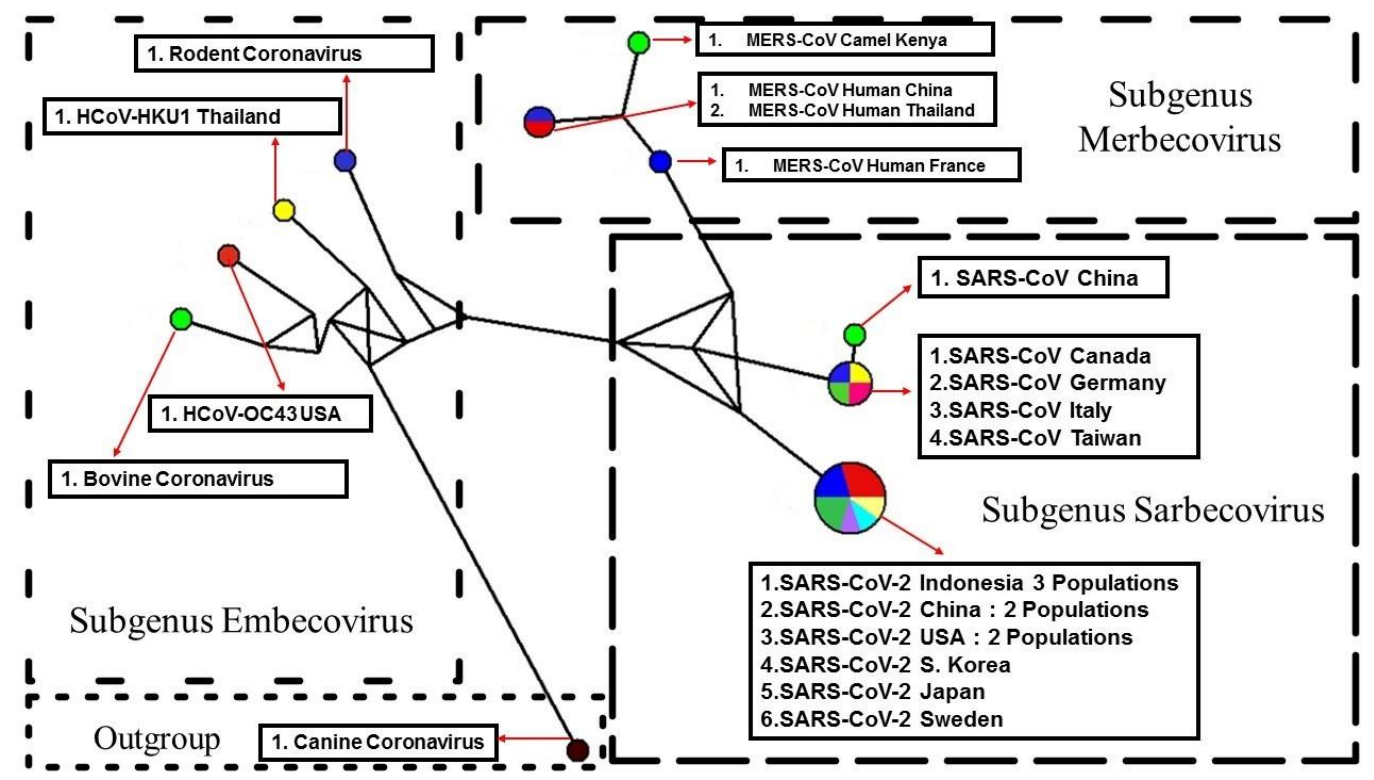

Figure 3. Haplotype network of 23 species of Betacoronavirus and an outgroup from Alphacoronavirus. Circles representing haplotypes, larger the circle more populations they have. Colour from circles shows the proportion of the populations from countries. Closer the distance between haplotypes the more genetic similarities.

\section{Haplotype Network and Gene Flow}

Haplotype reconstruction revealed that all analyzed Betacoronaviruses were divided into 3 main groups with total 11 haplotypes was discovered. This separation represents their subgenus, i.e. group 1 with SARS-CoV and SARS-CoV-2 from Sarbecovirus, group 2 with MERS-CoV from Merbecovirus, and group 3 with HCoV-HKU1, HCoV-OC43, Rodent Coronavirus and Bovine Coronavirus from Embecovirus. SARS-CoV-2 clumped in one haplotype, while SARS-CoV split into 
two different haplotypes with SARS-CoV from China has their one. In line with phylogenetic result, Rodent $\mathrm{CoV}$ and Bovine $\mathrm{CoV}$ have a close relationship with previously identified human coronavirus (Fig. 3). This was supported by sequence similarity results where Rodent and Bovine Coronavirus have relatively high similarity with $\mathrm{HCoV}$ HKU1 (Fig. 4). Therefore, there is a big probability of future zoonosis from bovine and rodent due to adjacent similarity of their contained coronavirus. Gene flow analysis from DNASP shows that among SARS-CoV-2 used in this research, nucleotide diversity was 0.00022 and the average number of nucleotides was 6.5333 . Gene flow strength between the China population and other populations was very high with $\mathrm{Gst}=0.03498$ and $\mathrm{Nm}=$ 6.90. Thus, we know that the transmission rate is high.

\section{Discussion}

Human-pathogenic coronavirus belongs to subfamily coronavirinae, which consists of Alphacoronavirus, Betacoronavirus, Gammacoronavirus, and Deltacoronavirus (Cui et al., 2019). With the current health crisis, Betacoronavirus has extensively studied due to its ability to cause pandemic over time. SARS-CoV, MERS-CoV, and SARS-CoV-2 are the member of Betacoronavirus which are familiar after causing global outbreak such as SARS, MERS, and Covid-19 (Cui et al.,
2019). Genetic structure of Betacoronavirus, in particular SARS-CoV-2, has been studied previously (Chen et al., 2020; Khailany et al., 2020). These studies confirm that each of Betacoronavirus members have similarities among each other's (Fig. 1). Furthermore, several point mutations in SARS-CoV-2 also discovered locating in ORF1a, ORF1b, S Protein, ORF6, ORF7a, ORF8, and $\mathrm{NC}$ region. Mutation in virus originated from genome replication error. In the case of DNA virus, there are proofreading that slows down replication error, but SARS-CoV-2 is an RNA virus that lack of proofreading (Peck \& Lauring, 2018). Besides, the high rate of gene flow also influences virus mutation (Rubio et al., 2013). ORF1a encodes polypeptide pp1a, responsible to form the replication-transcription complex after processed by Main Protease (MPro) (Chen et al., 2020). Similarly, protein from ORF8 also contributes to the weakening of immune response by suppressing Major Histocompatibility Complex class I (MHC I) which has an important role for elimination of virus-infected cells (Zhang et al., 2020). Moreover, ORF8 protein showed a high possibility as a factor during inter-species transmission (Lau et al., 2015). Regarding those important roles of ORF1a, and ORF8, a mutation in those regions should be studied more to observe potential role in the severity and dispersion of coronavirus-related diseases.

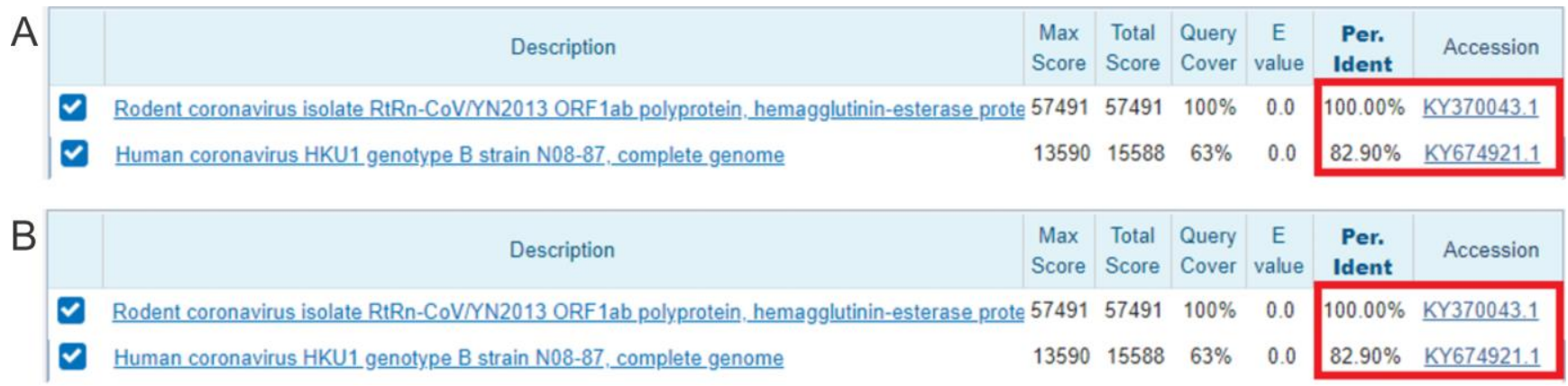

Figure 4. BLAST result. (A) Rodent coronavirus with HCoV-HKU1, and (B) Bovine coronavirus with HCoV-OC43.

Either phylogenetic or haplotype network analysis consistently showed that the Betacoronavirus grouped into their respective subgenus (Fig. 2 and 3). Betacoronavirus is divided into 4 lineages, including lineage A (Embecovirus), B (Sarbecovirus), C (Merbecovirus), and D (Nobecovirus) (Drexler et al., 2014; Fahmi et al., 2020; Wassenaar \& Zou, 2020). Embecovirus has two PL ${ }^{\mathrm{PRO}}$ (papain-like protease), that are $\mathrm{PL} 1^{\mathrm{PRO}}$ and $\mathrm{PL} 2{ }^{\mathrm{PRO}}$, while the other Betacoronavirus only has 1 type of PLpro. It is known that Embecovirus also has Haemagglutinin Esterase (HE) gene (Woo et al., 2010). Merbecovirus and Sarbecovirus probably use DPP4 and ACE2 receptors, but in affinity, gradient binds to different host receptors (Wong et al., 2019).

Based on Figure 2-4, it showed that there are proximity between HCov-OC43 with Bovine Coronavirus and HCoV-HKU1 with Rodent Coronavirus. Factors that increase the occurrence of zoonosis are phylogenetic closeness, RNA building receptor similarity, and interactions between human and animals, thus increasing a virus movement to a new host and become new virus strain (Olival et al., 2017). Thus, the relation among those species could indicate the possibility of future zoonosis to human. $\mathrm{HCoV}-\mathrm{OC} 43$ and $\mathrm{HCoV}-\mathrm{HKU} 1$ are viruses that infect human. $\mathrm{HCoV}-\mathrm{OC} 43$ is a zoonotic virus from rodent that is infecting through bovine, while $\mathrm{HCoV}$ HKU1 caused by a rodent (Cui et al., 2019; Ye et al., 2020). Bovine CoV is closely related to HCoV-OC43, so there is a possibility of zoonosis disease to human because of their genetic similarity up to $97.42 \%$ (Szczepanski et al., 2019). Bovine $\mathrm{CoV}$ has the same receptor as $\mathrm{HCoV}-\mathrm{OC} 43$, so it is possible to transmit into human like HCoV-OC43 (Szczepanski et al., 2019). $\mathrm{HCoV}-\mathrm{OC} 43$ is transmitted from rodent to human through bovine using a 9-O-acetic acid receptor on ciliated epithelial cells. The virus can adapt to its new host and began to mutate (Pyrc et al., 2010; Ye et al., 2020). Rodent $\mathrm{CoV}$ also has a possibility to start animal-human transmission due to the closeness to HCoV-HKU1 and has genetic similarity up to $82.90 \%$ (Fig. 4). That zoonosis can occur directly or indirectly through intermediate hosts to human (Ye et al., 2020). 
The studies conclude that phylogenetic and haplotype network showed that beta coronavirus forms 4 groups of their origin from animal and human with high similarity of their genome. With the close relationship of Bovine $\mathrm{CoV}$ and Rodent $\mathrm{CoV}$, it's highly predicted that this virus has a probability to transmit into human in the future.

\section{Acknowledgment}

Thanks to Bioinformatics lecturer and assistant, especially Feri Eko Hermanto S.Si., M.Si for assisting of the in silico analyses and English writing.

\section{References}

Bandelt, H. J., Forster, P., \& Röhl, A. (1999). Median-joining networks for inferring intraspecific phylogenies. Molecular Biology and Evolution, 16(1), 37-48. doi:10.1093/oxfordjournals.molbev.a026036

Chan, J. F. -W., Yuan, S., Kok, K. H., To, K. K. -W., Chu, H., Yang, J., Xing, F., Liu, J., Yip, C. C. -Y., Poon, R. W. -S., Tsai, H. W., Lo, S. K. -F., Chan, K. H., Poon, V. K. -M., Chan, W. M., Ip, J. D., Cai, J. P., Cheng, V. C. -C., Chen, H., Hui, C. K. -M., \& Yuen, K. Y. (2020). A Familial Cluster of Pneumonia Associated with The 2019 Novel Coronavirus Indicating Person-to-person Transmission: a Study of Family Cluster. The Lancet, 395 (10223), 514-523. doi:10.1016/S01406736(20)30154-9

Chen, Y., Liu, Q., \& Guo, D. (2020). Emerging coronaviruses: Genome structure, replication, and pathogenesis. Journal of Medical Virology, 92(4), 418-423. doi:10.1002/jmv.25681

Cui, J., Li, F., \& Shi, Z.-L. (2019). Origin and evolution of pathogenic coronaviruses. Nature Reviews. Microbiology, 17(3), 181-192. doi:10.1038/s41579-018-0118-9

Decaro, N., Mari, V., Dowgier, G., Elia, G., Lanave, G., Colaianni, M. L., \& Buonavoglia,C. (2015). Full-genome Sequence of Pantropic Canine Coronavirus. Genome Announc, 3(3). doi:10.1128/genomeA.00401-15.

de Wit, E., van Doremalen, N., Falzarano, D., \& Munster, V. J. (2016) SARS and MERS: Recent insights into emerging coronaviruses. Nature Reviews. Microbiology, 14(8), 523-534. doi:10.1038/nrmicro.2016.81

Drexler, J. F., Corman, V. M., \& Drosten, C. (2014). Ecology, evolution and classification of bat coronaviruses in the aftermath of SARS. Antiviral Research, 101, 45-56. doi:10.1016/j.antiviral.2013.10.013

Du, B., Qiu, H. B., Zhan, X., Wang, Y. S., Kang, H. Y. J., Li, X. Y., Wang, F., Sun, B., \& Tong, Z. H. (2020). [Pharmacotherapeutics for the New Coronavirus Pneumonia]. Zhonghua Jie He He Hu Xi Za Zhi = Zhonghua Jiehe He Huxi Zazhi $=$ Chinese Journal of Tuberculosis and Respiratory Diseases, 43(0), E012. doi:10.3760/cma.j.issn.10010939.2020.0012

Fahmi, M., Kubota, Y., \& Ito, M. (2020). Nonstructural proteins NS7b and NS8 are likely to be phylogenetically associated with evolution of 2019-nCoV. Infection, Genetics and Evolution: Journal of Molecular Epidemiology and Evolutionary Genetics in Infectious Diseases, 81, 104272. doi:10.1016/j.meegid.2020.104272

Fluxus Technology. (2020). Free Phylogenetic Network Software (Version 10.0.0) [Computer software]. Fluxus Technology Ltd. https://www.fluxus-engineering.com/

He, R., Dobie, F., Ballantine, M., Leeson, A., Li, Y., Bastien, N., Cutts, T., Andonov, A., Cao, J., Booth, T. F., Plummer, F. A., Tyler, S., Baker, L., \& Li, X. (2004). Analysis of Multimerization of The SARS Coronavirus Nucleocapsid Protein. Biochem. Biophys. Res. Commun., $316 \quad$ (2), 476-483. doi:10.1016/j.bbrc.2004.02.074.

Hwang, J. \& Cho, G. (2018). Identification of novel haplotypes and interpretation of gene flow of mitochondrial DNA control region of Eurasian otter (Lutra lutra) for the effective conservation. Journal of Veterinary Medical Science, 80(11), 1791-1800. doi:10.1292/jvms.17-0678.
Issa, E., Merhi, G., Panossian, B., Salloum, T., \& Tokajian, S. (2020). SARS-CoV-2 and ORF3a: Nonsynonymous Mutations, Functional Domains, and Viral Pathogenesis. MSystems, 5(3). doi:10.1128/mSystems.00266-20

Ji, W., Wang, W., Zhao, X., Zai, J., \& Li, X. (2020). Cross-species transmission of the newly identified coronavirus $2019-\mathrm{nCoV}$. Journal of Medical Virology, 92(4), 433-440. doi:10.1002/jmv.25682

Khailany, R. A., Safdar, M., \& Ozaslan, M. (2020). Genomic characterization of a novel SARS-CoV-2. Gene Reports, 19, 100682. doi:10.1016/j.genrep.2020.100682

Kumar, S., Stecher, G., Li, M., Knyaz, C., \& Tamura, K. (2018). MEGA $\mathrm{X}$ : Molecular Evolutionary Genetics Analysis across Computing Platforms. Molecular Biology and Evolution, 35(6), 1547-1549. doi:10.1093/molbev/msy096

Lau, S. K. P., Feng, Y., Chen, H., Luk, H. K. H., Yang, W.-H., Li, K. S M., Zhang, Y.-Z., Huang, Y., Song, Z.-Z., Chow, W.-N., Fan, R. Y. Y., Ahmed, S. S., Yeung, H. C., Lam, C. S. F., Cai, J.-P., Wong, S. S. Y., Chan, J. F. W., Yuen, K.-Y., Zhang, H.-L., \& Woo, P. C. Y. (2015). Severe Acute Respiratory Syndrome (SARS) Coronavirus ORF8 Protein Is Acquired from SARSRelated Coronavirus from Greater Horseshoe Bats through Recombination. Journal of Virology, 89(20), 10532-10547. doi:10.1128/JVI.01048-15

Lu, L., Van Dung, N., Ivens, A., Bogaardt, C., O’Toole, A., Bryant, J. E., Carrique-Mas, J., Van Cuong, N., Anh, P. H., Rabaa, M. A. Tue, N. T., Thwaites, G. E., Baker, S., Simmonds, P., \& Woolhouse, M. E. (2018). Genetic diversity and cross-species transmission of kobuviruses in Vietnam. Virus Evolution, 4(1). doi:10.1093/ve/vey002

Lu, R., Wang, Y., Wang, W., Nie, K., Zhao, Y., Su, J., Deng, Y., Zhou, W., Li, Y., Wang, H., Wang, W., Ke, C., Ma, X., Wu, G. \& Tan, W. (2015). Complete Genome Sequence of Middle East Respiratory Syndrome Coronavirus (MERS-CoV) from the First Case in China. Genome Announc, 3 (4). doi:10.1128/genomeA.00818-15.

Miller, M. A., Pfeiffer, W., \& Schwartz, T. (2010). Creating the CIPRES Science Gateway for inference of large phylogenetic trees. 2010 Gateway Computing Environments Workshop (GCE), 18. doi:10.1109/GCE.2010.5676129

Nei, M. (1973). Analysis of Gene Diversity in Subdivided Populations. Proc. Nat. Acad. Sci. USA, 70(12), 3321-3323. doi:10.1073/pnas.70.12.3321.

NCBI. (2020). Basic Local Alignment Search Tool. National Center of Biotechnology Information, U.S National Library of Medicine. https://blast.ncbi.nlm.nih.gov/Blast.cgi.

Olival, K. J., Hosseini, P. R., Zambrana-Torrelio, C., Ross, N., Bogich, T. L., \& Daszak, P. (2017). Host and viral traits predict zoonotic spillover from mammals. Nature, 546(7660), 646650. doi:10.1038/nature22975

Ommeh, S., Zhang, W., Zohaib, A., Chen, J., Zhang, H., Hu, B., Ge, X Y., Yang, X. L., Masika, M., Obanda, V., Luo, Y., Li, S., Waruhiu, C., Li, B., Zhu, Y., Ouma, D., Odendo, V., Wang, L. F., Anderson, D. E., Lichoti, J., Mungube, E., Gakuya, F., Zhou, P., Ngeiywa, K. J., Yan, B., Agwanda, B. \& Shi, Z. L. (2018). Genetic evidence of Middle East Respiratory Syndrome Coronavirus (MERS-Cov) and Widespread Seroprevalence Among Camels in Kenya. Virol Sin, 33 (6), 484-492. doi:10.1007/s12250-018-0076-4.

Peck, K. M. \& A. S. Lauring. (2018). Complexities of Viral Mutation Rates. Journal of Virology, 92(14), e01031-17. doi:10.1128/JVI.01031-17.

Plipat, T., Buathong, R., Wacharapluesadee, S., Siriarayapon, P., Pittayawonganon, C., Sangsajja, C., Kaewpom, T., Petcharat, S., Ponpinit, T., Jumpasri, J., Joyjinda, Y., Rodpan, A., Ghai, S., Jittmittraphap, A., Khongwichit, S., Smith, D. R., Corman, V. M., Drosten, C., \& Hemachudha, T. (2017). Imported Case of Middle East Respiratory Syndrome Coronavirus (MERSCoV) Infection from Oman to Thailand, June 2015. Euro Surveill, 22 (33), 30598. doi:10.2807/1560-7917.

Pyrc, K., Sims, A. C., Dijkman, R., Jebbink, M., Long, C., Deming, D., Donaldson, E., Vabret, A., Baric, R., van der Hoek, L., \& Pickles, R. (2010). Culturing the unculturable: Human coronavirus HKU1 infects, replicates, and produces progeny virions in human ciliated airway epithelial cell cultures. Journal of Virology, 84(21), 11255-11263. doi:10.1128/JVI.00947-10 
Rambaut, A. (2018). Figtree, a graphical viewer of phylogenetic trees (Version 1.4.4) [Computer software]

Rozas, J., Ferrer-Mata, A., Sánchez-DelBarrio, J. C., Guirao-Rico, S., Librado, P., Ramos-Onsins, S. E., \& Sánchez-Gracia, A (2017). DnaSP 6: DNA Sequence Polymorphism Analysis of Large Data Sets. Molecular Biology and Evolution, 34(12), 3299-3302. doi:10.1093/molbev/msx248

Rubio, L., Guerri, J., Moreno, P. (2013). Genetic variability and evolutionary dynamics of viruses of the family Closteroviridae. Front. Microbiol., 4: 151. doi:10.3389/fmicb.2013.00151.

Siu, K.-L., Yuen, K.-S., Castaño-Rodriguez, C., Ye, Z.-W., Yeung, M.L., Fung, S.-Y., Yuan, S., Chan, C.-P., Yuen, K.-Y., Enjuanes, L., \& Jin, D.-Y. (2019). Severe acute respiratory syndrome coronavirus ORF3a protein activates the NLRP3 inflammasome by promoting TRAF3-dependent ubiquitination of ASC. The FASEB Journal, 33(8), 8865-8877. doi:10.1096/fj.201802418R

Suzuki, T., Otake, Y., Uchimoto, S., Hasebe, A., \& Goto, Y. (2020). Genomic Characterization and Phylogenetic Classidication of Bovine Coronaviruses Through Whole Genome Sequence Analysis. Viruses, 12(183). doi:10.3390/v12020183.

Szczepanski, A., Owczarek, K., Bzowska, M., Gula, K., Drebot, I., Ochman, M., Maksym, B., Rajfur, Z., Mitchell, J. A., \& Pyrc, K. (2019). Canine Respiratory Coronavirus, Bovine Coronavirus, and Human Coronavirus OC43: Receptors and Attachment Factors. Viruses, 11(4). doi:10.3390/v11040328

Thiel, V., Ivanov, K. A., Putics, A., Hertzig, T., Schelle, B., Bayer, S., Weissbrich, B., Snijder, E. J., Rabenau, H., Doerr, H. W. Gorbalenya, A. E., \& Ziebuhr, J. (2003). Mechanism and Enzymes Involved in SARS Coronavirus Genome Expression. J. Gen. Virol., 84(9), 2305-2315. doi:10.1099/vir.0.19424-0.

Vicenzi, E., Canducci, F., Pinna, D., Mancini, N., Carletti, S., Lazzarin, A., Bordignon, C., Poli, G., \& Clementi, M. (2004). Coronaviridae and SARS-Associated Coronavirus Strain HSR1 Emerging Infect. Dis., 10(3), 413-418. doi:10.3201/eid1003.030683.

Wassenaar, T. M., \& Zou, Y. (2020). 2019 nCoV/SARS-CoV-2: Rapid classification of betacoronaviruses and identification of Traditional Chinese Medicine as potential origin of zoonotic coronaviruses. Letters in Applied Microbiology, 70(5), 342348. doi:10.1111/lam.13285
Wong, A. C. P., Li, X., Lau, S. K. P., \& Woo, P. C. Y. (2019). Global Epidemiology of Bat Coronaviruses. Viruses, 11(2). doi:10.3390/v11020174

Woo, P. C. Y., Huang, Y., Lau, S. K. P., \& Yuen, K.-Y. (2010). Coronavirus Genomics and Bioinformatics Analysis. Viruses, 2(8), 1804-1820. doi:10.3390/v2081803

Woo, P. C. Y., Lau, S. K. P., Huang, Y., \& Yuen, K.-Y. (2009). Coronavirus diversity, phylogeny and interspecies jumping. Experimental Biology and Medicine (Maywood, N.J.), 234(10), 1117-1127. doi:10.3181/0903-MR-94

Wu, F., Zhao, S., Yu, B., Chen, Y. M., Wang, W., Song, Z. G., Hu, Y., Tao, Z. W., Tian, J. H., Pei, Y. Y., Yuan, M. L., Zhang, Y. L., Dai, F. H., Liu, Y., Wang, Q. M., Zheng, J. J., Xu, L., Holmes, E. C., \& Zhang, Y. Z. (2020). A New Coronavirus Associated with Human Respiratory Disease in China. Nature, 579(7798), 265-269. doi:10.1038/s41586-020-2008-3.

Wu, Z., Lu, L., Du, J., Yang, L., Ren, X., Liu, B., Jiang, J., Yang, J., Dong, J., Sun, L., Zhu, Y., Li, Y., Zheng, D., Zhang, C., Su, H., Zheng, Y., Zhou, H., Zhu, G., Li, H., Chmura, A., Yang, F., Daszak, P., Wang, J., Liu, Q., \& Jin,Q. (2018). Comparative Analysis of Rodent and Small Mammal Viromes to Better Understand The Wildlife Origin of Emerging Infectious Diseases. Microbiome, 6(1). 178. doi:10.1186/s40168-0180554-9.

Yang, F., Li, X., Li, Q., Li, T. (2014). Exploring the diversity in cluster ensemble generation: Random sampling and random projection. Expert Systems with Applications, 41(10), 4844-4866. doi:10.1016/j.eswa.2014.01.028.

Ye, Z.-W., Yuan, S., Yuen, K.-S., Fung, S.-Y., Chan, C.-P., \& Jin, D.-Y. (2020). Zoonotic origins of human coronaviruses. International Journal of Biological Sciences, 16(10), 1686-1697. doi:10.7150/ijbs.45472

Zhang, Y., Zhang, J., Chen, Y., Luo, B., Yuan, Y., Huang, F., Yang, T., Yu, F., Liu, J., Liu, B., Song, Z., Chen, J., Pan, T., Zhang, X., Li, Y., Li, R., Huang, W., Xiao, F., \& Zhang, H. (2020). The ORF8 Protein of SARS-CoV-2 Mediates Immune Evasion through Potently Downregulating MHC-I. BioRxiv, 2020.05.24.111823. doi: $10.1101 / 2020.05 .24 .111823$ 